\title{
Enfrentando a mastectomia: análise dos relatos de mulheres mastectomizadas sobre questões ligadas à sexualidade
}

\author{
Tânia Pires Duarte \\ Ângela Nobre de Andrade \\ Universidade Federal do Espírito Santo
}

\begin{abstract}
Resumo
Este trabalho se propôs a investigar como seis mulheres mastectomizadas, com idades de 37 a 55 anos, e com tempo de cirurgia de 1 ano e meio a 8 anos, percebiam a sua sexualidade. Para exame dos relatos foi aplicada a técnica de análise de conteúdo, em que foram identificadas as seguintes categorias: informação sobre a doença, reação ao diagnóstico, relação médico-paciente, eu e o meu corpo, eu e o olhar do outro, percepção de si mesma e relacionamentos amorosos. A análise dessas categorias demonstrou que, após a mastectomia, as mulheres apresentaram algumas limitações e dificuldades em lidar com situações que envolviam a exposição do próprio corpo. No entanto, apesar dos temores, algumas mulheres produziram diversos modos de (re)significarem e expressarem a sua sexualidade de uma forma potencializadora para suas relações cotidianas.
\end{abstract}

Palavras-chave: sexualidade, mastectomia, enfrentamento da doença, câncer de mama.

\begin{abstract}
Facing mastectomy: analysis of the discourse of mastectomized women about questions of sexuality. This research intended to analyze the self-perception of sexuality of six 37 to 55 year old women who had been submitted to radical mastectomy one and a half to eight years before. For this analysis, the author chose the technique of content analysis, according to which the following categories were identified: information about the disease, reaction to the diagnosis, relationship doctor-patient, my body and I, somebody else's look and I, looking at herself and love affairs. The analysis of these categories showed that after the mastectomy the women developed some limitation and difficulty in handling certain situations, which involved the exposition of their body. Despite their fears, however, some women generated new ways to understand and express their sexuality, giving new impulse to their daily relationships.
\end{abstract}

Keywords: Sexuality, mastectomy, disease coping, breast cancer.

$\mathrm{E}$ m Psicologia os estudos sobre as implicações da mastectomia para a sexualidade da mulher são recentes e apoiados em várias abordagens teóricas, sendo que cada uma possui um "olhar" sobre o fenômeno, conforme os seus pressupostos teóricos. Dentre essas abordagens, destacam-se as chamadas "psicologizantes" que, segundo Sant'Ana (1997), foram diretamente influenciadas pela psicanálise, nos anos 60 e 70, e que atribuem as causas do câncer de mama a experiências subjetivas dolorosas. Essas abordagens preconizam que a doença é produzida pelo próprio sujeito. Intensificando de uma certa forma o sentimento de autoresponsabilização pelo surgimento da doença (Cox \& Mackay, 1981). Em contraponto, as produções científicas sobre os fatores psicossociais do câncer de mama vêm sendo estudados desde a década de 80 , numa tentativa de demonstrar que o câncer de mama representa um problema de saúde pública com grandes proporções.
O presente trabalho objetivou compreender como as mulheres mastectomizadas percebem a própria sexualidade, uma vez que um acometimento como o câncer de mama é visto como potencialmente estressor e provoca uma série de transformações na vida, tanto da mulher acometida quanto de seus familiares, pois além do medo da morte que a doença suscita, há, também, a ameaça da mutilação da mama, que é um símbolo importante de feminilidade, sexualidade, erotismo, maternidade e outros.

A incidência do câncer de mama e suas principais formas de prevenção

O câncer de mama, dentre as neoplasias malignas, tem sido o responsável pelos maiores índices de mortalidade no mundo, tornando-se uma das grandes preocupações em saúde pública, no que diz respeito à saúde da mulher. A Sociedade Americana de Câncer estimou para o ano 2000, aproxima- 
damente um milhão de novos casos em todo o mundo (Instituto Nacional do Câncer, 2000).

No Brasil, segundo dados do Ministério da Saúde, o câncer de mama representa uma das primeiras causas de óbitos em mulheres, sendo apenas superado pelas mortes provocadas por doenças cardiovasculares e causas externas (acidentes de trânsito e violência urbana). Este fato situa o câncer de mama como a terceira causa responsável pelo índice de grande mortalidade em mulheres no país, principalmente nas regiões sul e sudeste, o que indica uma mudança no perfil de mortalidade, em que as doenças crônicodegenerativas, comparadas às doenças infecto-contagiosas que causavam muitas mortes até a década de 80 , apresentam uma alta prevalência entre a população brasileira (Instituto Nacional do Câncer, 2000).

No Brasil, estudos estatísticos realizados pelo Sistema de Informação sobre Mortalidade (SIM), órgão do Ministério da Saúde criado em 1975, demonstram que, no ano de 1997, foram registrados 7.664 mortes provocadas por câncer de mama (Instituto Nacional do Câncer, 2000). A estimativa de casos novos, esperados para o ano 2000, de mulheres com câncer de mama é de 28.340 casos que serão responsáveis por 8.245 óbitos.

O Instituto Nacional do Câncer (INCA), órgão do Ministério da Saúde responsável, entre outras ações, pela prevenção dos mais variados tipos de câncer, admite que a maioria das ações dirigidas para o controle do câncer de mama são voltadas para a sua detecção precoce. De acordo com esse órgão governamental, um grupo de trabalho está sendo criado para traçar estratégias de enfrentamento do câncer de mama em todo o Brasil. Essas estratégias consistem em orientar 500 mil mulheres e capacitar 100 mil profissionais da área de saúde.

São três as ações de saúde consideradas fundamentais para o diagnóstico precoce do câncer de mama: a) auto-exame das mamas, AEM, realizado de forma adequada; b) exame clínico das mamas, ECM, feito por um profissional especializado e; c) mamografia (Instituto Nacional do Câncer, 1997). Essas ações podem contribuir para que, no surgimento de um tumor maligno, o tratamento apropriado não requeira uma intervenção cirúrgica agressiva para o corpo feminino.

\section{O significado do câncer de mama}

O câncer de mama ou carcinoma mamário é o resultado de multiplicações desordenadas de determinadas células que se reproduzem em grande velocidade, desencadeando o aparecimento de tumores ou neoplasias malignas que podem vir a afetar os tecidos vizinhos e provocar metástases. Este tipo de câncer aparece sob forma de nódulos e, na maioria da vezes, podem ser identificados pelas próprias mulheres, por meio da prática do auto-exame (Gomes, 1987).

Os variados tipos de câncer são classificados conforme o local do corpo humano em que a doença se instala. No tecido de revestimento em nível da pele, mucosas e glândulas encontram-se os carcinomas, que podem ser não-invasivos ou invasivos, como o carcinoma mamário. Quanto ao diag- nóstico laboratorial do câncer da mama, a comunidade internacional reconhece dois sistemas. Um deles é denominado o sistema TNM, criado pelo médico francês Pierre Denoix, que classifica a doença em três fases: $\mathrm{T}$, tumor; $\mathrm{N}$, linfonodos axilares homolaterais; $\mathrm{M}$, metástases à distância. O outro sistema, complementar a esse, identifica a doença por estágio. O câncer de mama ou carcinoma mamário evolui em estágios que variam de 0-IV, crescente por ordem de gravidade da doença. Em resumo, a realização do diagnóstico do câncer depende desta classificação que revela o grau de comprometimento da área atingida, bem como o prognóstico e tratamento a ser indicado (Dousset, 1999; Gomes, 1987).

As atividades terapêuticas são planejadas de acordo com esses estágios. É imprescindível o conhecimento do estágio clínico da paciente, visto que este permite estabelecer a extensão da área atingida e a gravidade da doença, além de planejar um tratamento adequado, assim como o prognóstico. A escolha do método terapêutico apropriado irá depender, também, de vários fatores, tais como a idade da paciente, a localização e o tamanho do tumor, a disponibilidade financeira, a análise da mamografia e o modo da paciente lidar com a mama afetada (Malzyner, 1997).

\section{Câncer de mama: um desafio para a saúde pública}

As ações de prevenção descritas anteriormente têm merecido atenção especial de vários profissionais e estudiosos das áreas humanas e sociais (por exemplo, psicologia, epidemiologia, sociologia), preocupadas com a questão da educação voltada para a saúde, uma vez que as doenças classificadas como crônico-degenerativas podem estar associadas às condições e qualidade de vida dos indivíduos.

A preocupação com o aumento de casos de mulheres com câncer de mama avançado tornou-se um problema atual da saúde pública e: “(...) tem colocado a necessidade de se investigar a complexa relação entre conhecimento, crenças, atitudes e comportamentos de saúde” (Seidl \& Gimenes, 1997, p. 260).

Estudiosos do assunto afirmam que, apesar de toda informação sobre a importância da realização do auto-exame, divulgada principalmente nos meios de comunicação e pelos programas de assistência à saúde da mulher, as mulheres não têm sido estimuladas o bastante para realizarem o auto-exame. No que diz respeito à influência de fatores sócio-econômicos na adesão a essa prática, alguns estudos em psicologia demonstram que mulheres com maior nível de renda e nível de instrução são as que mais aderem e possuem conhecimento sobre o auto-exame das mamas (Seidl \& Gimenes, 1997; Gonçalves \& Dias, 1999).

Para Gonçalves e Dias (1999), esses estudos vêm corroborar a idéia de que as campanhas educativas que abordam a prevenção do câncer de mama precisam ser destinadas e adaptadas à realidade da população feminina de baixa renda e de baixa escolaridade. Na maioria das vezes, as mulheres em questão não têm acesso a um serviço público de saúde de qualidade e, quando o procuram, a doença já se encontra em 
estágio avançado. Além disso, não se conhece profundamente as percepções, crenças, níveis de informação que essas mulheres têm a respeito do auto-exame, para que se possa traçar estratégias educativas no sentido de melhor orientá-las.

\section{Principais formas de tratamento do câncer de mama}

$\mathrm{O}$ registro mais antigo sobre as formas de tratamento do câncer de mama, assim como a sua descrição, foram encontrados por Edwin Smith em 1962, em papiros egípcios datados do ano 3000 AC (Gomes, 1987).

No final do século XIX, o médico-cirurgião Hasteld descreveu e publicou os resultados de uma técnica inovadora de remoção cirúrgica que representaria a cura para o câncer de mama. Esta técnica, denominada mastectomia radical, consiste na retirada total da mama afetada pelo câncer e, por ser considerada um procedimento cirúrgico extremamente agressivo e traumático para a mulher, atualmente vem sendo substituída por outras cirurgias que evitam a mutilação. Essas inovações contribuíram para que a mastectomia radical não representasse a única forma de tratamento para o câncer de mama, dando lugar a cirurgias que preservam o corpo da mulher, como a quadranctomia e lumpectomia. Além disso, mesmo realizando a retirada da mama, há atualmente a possibilidade de reconstrução da mesma com utilização do silicone ou a partir da retirada do tecido do abdômen. A reconstrução da mama nesse âmbito representa uma possibilidade de reabilitação bastante atual para as mulheres que necessitam realizar a mastectomia radical como o tratamento principal para o câncer de mama. Essa reconstrução dependerá de vários aspectos: peso, altura, idade, tratamento prévio ou complementar com radioterapia, estado de saúde e outras cirurgias que a paciente já tenha realizado (Boff, 1999).

O avanço das técnicas de cirurgia plástica nos últimos anos tem proporcionado resultados satisfatórios para a expectativa estética e psicológica da mulher, ao reduzir o trauma causado pela mutilação. Desse modo, o surgimento e o desenvolvimento das técnicas coadjuvantes de radiologia e quimioterapia nos últimos quarenta anos, possibilitaram que o câncer de mama fosse tratado de forma multidisciplinar e integrada, alcançando maiores índices de sobrevida e qualidade de vida das mulheres acometidas por essa doença. Atualmente, a mastectomia somente é indicada para tumores avançados e consiste na retirada da mama afetada juntamente com os linfonodos axilares. A literatura consultada (Malzyner, 1997), no entanto, não explica os motivos pelos quais, nos Estados Unidos, a mastectomia radical é realizada somente em 3\% dos casos, ao passo que, no Brasil, de acordo com Souhami (1985, citado por Farstein, 1989), "um grande número de cirurgiões e radioterapeutas ainda continua relutante em aceitar uma nova forma terapêutica e permanece submetendo suas pacientes às formas mais radicais de terapia” (p. 180).

\section{Aspectos psicossociais do câncer de mama}

As mamas além de desempenharem um importante papel fisiológico em todas as fases do desenvolvimento feminino que vão desde a puberdade à idade adulta, também represen- tam em nossa cultura um símbolo de identificação da mulher e sua feminilidade expressas pelo erotismo, sensualidade e sexualidade. Ao considerar essas questões, o câncer de mama, ainda hoje, apesar dos progressos da medicina em relação aos métodos de diagnóstico e tratamento, é visto como uma "sentença de morte" pela maior parte das mulheres acometidas por essa doença. De acordo com pesquisadores e estudiosos da área, é um acontecimento marcante com implicações sociais, psicológicas e sexuais (Kovács, Amorim Filho \& Sgorlon, 1998; Boff, 1999). O câncer de mama representa uma ameaça em vários níveis. Os efeitos deletérios dessa doença (o medo da morte, da rejeição, de ser estigmatizada, da mutilação, da recidiva, dos efeitos da quimioterapia, incerteza quanto ao futuro e outros) têm preocupado os profissionais de saúde envolvidos com a qualidade de vida dessas pacientes. Sontag (1994) afirma que as várias metáforas construídas e partilhadas socialmente ao longo da história a respeito do câncer contribuem para que essa doença ainda hoje seja vista como uma sentença de morte. As representações do câncer remetem a uma doença cruel, corrosiva, contagiosa, estigmatizada e degradante, que consome o indivíduo aos poucos, sendo considerada, muitas vezes, um castigo de Deus.

O diagnóstico do câncer é visto como uma ameaça para a paciente e sua família em todos os níveis de suas vidas. A dinâmica familiar é alterada por ocasião da doença e vários medos começam a fazer parte do cotidiano.

Ao analisar a literatura especializada no assunto, podese observar que a preocupação central da mulher e sua família após receber o diagnóstico do câncer de mama é a sobrevivência. Em seguida, surge a preocupação com o tratamento e condições econômicas para realizá-lo. Por fim, há a preocupação com mutilação e desfiguração e suas conseqüências para a vida sexual da mulher (Gimenes \& Queiroz, 1997).

Pesquisas realizadas com pacientes diagnosticadas com câncer de mama demonstram que tanto o diagnóstico quanto o tratamento e suas seqüelas são muito estressantes para a mulher. Alguns estudiosos afirmam que a mama é um órgão que remete às representações que simbolizam a feminilidade, a estética, a sexualidade, imagem corporal e maternidade (Gimenes, 1997; Carver, 1993; Gandini, 1995).

Pesquisas vêm sendo desenvolvidas nos últimos vintes anos em psicologia sob enfoque, principalmente, da Teoria das Estratégias de Enfrentamento ou coping, elaborada por Folkman e Lazarus (1984), sendo definida como um processo dinâmico em que o indivíduo desenvolve diversas formas para lidar com determinadas situações que lhe sejam ameaçadoras. Dessa forma, esses estudos propõem-se a compreender as estratégias cognitivas, afetivas e comportamentais utilizadas pelas mulheres mastectomizadas para enfrentar as exigências que a doença lhes impõe.

Segal (1994) afirma que o câncer de mama provoca alterações no universo biopsicossocial da mulher acometida e a retirada da mama pode ocasionar vários danos. Após a mastectomia, a mulher pode vir a apresentar uma série de dificuldades ao reassumir a sua vida profissional, social, familiar e sexual. Dessa forma, para o universo pesquisado pela 
autora, esta fase (pós-cirurgia) é considerada extremamente difícil, longa e limitante para o exercício da sexualidade.

Uma outra questão discutida por autores da área é que as cirurgias mutiladoras, também podem afetar a percepção do próprio corpo, implicando em mudanças na imagem corporal que podem vir a afetar a sexualidade da paciente submetida a essas cirurgias (Chiozza, 1987; Kolb, 1980). Esta pode ser compreendida como a representação mental que temos do próprio corpo, estando diretamente vinculada à percepção e compondose dos aspectos fisiológicos, psico-afetivos, cognitivos e relacionais. Sob este ponto de vista, a imagem que fazemos do nosso corpo é construída e (des)construída ao longo de nossa vivência, a partir de experiências com o mundo exterior.

Com relação ao desempenho sexual após a mastectomia, Lim (1995), em um estudo realizado em Cingapura, aplicou a Escala de Ansiedade e Depressão em hospital geral (HAD ${ }^{1}$ Hospital Anxiety and Depression) e um questionário a 20 mulheres consideradas sexualmente ativas. As pacientes eram solicitadas a falar sobre sua vida sexual antes da doença, enfocando aspectos relacionados a freqüência de relações, desejo por atividade sexual e sobre a presença de dor e secura vaginal durante a relação. Foram também privilegiadas questões referentes às mudanças em suas atitudes, nas atitudes dos maridos, e no comportamento sexual de ambos após a mastectomia. Os resultados demonstraram que de 20, nove mulheres apresentaram problemas no relacionamento conjugal, como a diminuição na freqüência de relações sexuais. Neste grupo, também foram identificados mudanças no comportamento sexual, em que as mulheres evitavam despir-se diante dos parceiros e serem tocadas pelos mesmos. A utilização de sutiã e camisa durante as relações sexuais também foram relatadas pelas pacientes. Apesar de essas implicações terem sido consideradas negativas pelas mulheres, Lim (1995) afirma que a mastectomia não é a única causa dessa sensação de desconforto relatada pelas pacientes; há outros fatores antecedentes ao diagnóstico, que podem influenciar e intensificar o quadro de desconforto para a mulher acometida, como problemas financeiros, sociais, conjugais, idade da paciente, sua forma de lidar com situações adversas e também a falta de informação sobre a doença e suas conseqüências. Esse estudo também conclui que o esclarecimento sobre as questões referentes à sexualidade, na fase pós-cirúrgica, não são habitualmente abordados nas práticas médicas de rotina. E a cada dia cresce a necessidade desse esclarecimento, pois este é visto como fundamental para assegurar o bem-estar e a qualidade de vida das mulheres que vivenciam essa situação.

\section{Método}

\section{Participantes}

Participaram como informantes seis mulheres que residiam nos municípios de Vitória e Vila Velha, ES, com idades entre 34 e 55 anos. Três mulheres eram casadas e possuíam filhos, uma era divorciada e duas eram solteiras e não tinham filhos.

Todas as mulheres tiveram o diagnóstico de câncer de mama em estágio avançado da doença e foram submetidas à mastectomia radical, sendo que três optaram pela reconstru- ção da mama e três não realizaram essa cirurgia. O tempo transcorrido da cirurgia à época da entrevista compreendeu de 1 ano e meio a 8 anos. No que diz respeito à escolaridade das seis mulheres entrevistadas, três concluíram o nível superior e três possuíam o $2^{\underline{0}}$ grau completo. É importante ressaltar que foram utilizados nomes fictícios para resguardar as verdadeiras identidades das participantes da pesquisa.

\section{Instrumentos e procedimentos}

Como técnica de coleta de dados optou-se por entrevistas não-dirigidas, que tiveram uma duração média de 60 minutos. Esse recurso metodológico permitiu que as entrevistadas falassem livremente sobre o processo de adoecer e as questões relacionadas à vivência da sexualidade, assim como de suas relações cotidianas, valores e transformações percebidas após a cirurgia, com grande riqueza de detalhes. As entrevistas não seguiram uma sequência pré-estabelecida, o direcionamento dos relatos ficou a critério das informantes. Incialmente, após a apresentação, eu solicitava a participante que discorresse sobre o seu processo de adoecimento. Ao lançar esta questão num clima agradável de conversa, as participantes respondiam selecionando tanto os fatos objetivos, como a data da descoberta do nódulo, características anatômicas do tumor encontrado, quanto os fatos subjetivos, como as reações emocionais ao diagnóstico, o medo da morte, as dificuldades em relacionar-se com o próprio corpo, com o parceiro e os demais obstáculos enfrentados no decorrer da doença.

$\mathrm{O}$ primeiro passo dado para o acesso às informantes foi por telefone, quando foram explicados os motivos pelos quais elas estavam sendo convidadas a participar da pesquisa. Os locais dos encontros ficaram a critério das participantes. Quatro entrevistas foram feitas na própria casa das informantes e duas no ambiente de trabalho, após o horário de expediente. Para o registro dos relatos, foi utilizado o gravador, após o consentimento verbal das entrevistadas.

Para a análise das entrevistas, optou-se pela análise de conteúdo (Bardin, 1977). Essa técnica possibilitou a compreensão dos significados atribuídos pelas mulheres mastectomizadas à experiência do adoecer e à sua sexualidade após a cirurgia.

\section{Resultados e discussão}

A escolha da abordagem qualitativa como opção metodológica para a realização deste estudo permitiu-me compreender a realidade cotidiana das mulheres mastectomizadas, além de apreender os significados dados a experiência da sexualidade dentro do processo de adoecimento. Granger (1967, citado por Minayo, 1999) enfatiza que a pesquisa qualitativa em saúde possibilta ao pesquisador “(...) trabalhar com a percepção do vivido, com os significados das motivações, atitudes e valores” (p. 133).

Após transcrição e leitura dos relatos, foi realizada a seleção das temáticas que apareceram como as mais destacadas nas falas das informantes, ou seja, aquilo que estava sendo mais importante e problematizado e que era pertinente 
aos objetivos da pesquisa. O levantamento das categorias proporcionou uma aproximação da realidade vivenciada pelas mulheres mastectomizadas desde a descoberta do nódulo até as afetações produzidas pela perda da mama e suas implicações na sexualidade. Os temas contemplados pelas informantes são descritos nos parágrafos abaixo.

Informação sobre a doença. As falas referentes a essa questão permearam todas as outras temáticas. Nesta categoria, as entrevistadas falaram a respeito da importância da informação sobre a doença e suas consequências. Essas informações e orientações repassadas pelos meios de comunicação, profissionais da área de saúde e pessoas que vivenciaram a doença, sobre as causas do câncer de mama, aspectos relacionados à prevenção do câncer e suas implicações para a vida da mulher foram consideradas fundamentais para diminuir a ansiedade e o medo frente ao diagnóstico e tratamento. Os trechos descritos abaixo ilustram a importância que duas mulheres atribuíram à informação ao longo do processo de adoecimento.

E hoje vejo que, se tivesse mais informação, a minha realidade seria outra, eu teria buscado ajuda logo no início (Júlia).

O médico falou que tinha dado positivo, até então eu fiquei perturbada. Porque você não tem noção do que é. Então, para mim quer dizer foi um choque, deu positivo, mas sem saber o que era aquilo ali, positivo em relação à doença, mas o que era? O que vai ser? Eu não sabia nada disso (Elza).

Relação médico-paciente. Foram destacados os aspectos relacionados à formação e competência técnica do profissional da área médica, pois este profissional, na percepção das mulheres, desempenha um papel decisivo nos processos de diagnóstico e tratamento. O médico é o principal referencial da paciente, tanto no que tange aos aspectos objetivos que envolvem o tratamento da doença (escolha do procedimento cirúrgico, quimioterapia, radioterapia e outros), quanto aos aspectos subjetivos (expectativas, insegurança, medos, angústias, depressão e outros).

Todas as entrevistadas relataram ter identificado, de forma casual, o nódulo na mama. Em momento algum da entrevista fizeram menção à prática do auto-exame da mama, porém, relataram que, antes do surgimento da doença, estavam sendo acompanhadas por um ginecologista e que realizavam os exames preventivos de rotina, inclusive o exame clínico das mamas. Quatro mulheres relataram que, apesar da preocupação com a mama, pois algumas sentiam dores na axila, os médicos responsáveis não procuraram solucionar o problema de forma adequada. Assim, com o diagnóstico do câncer veio a confirmação de que a doença já estava em estágio avançado o que implicou em possibilidades terapêuticas mais agressivas. Algumas entrevistadas culparam os seus médicos:

Eu sempre fui ao ginecologista, mas ele nunca olhou o meu seio, nunca passou uma mamografia. O certo é fazer a mamografia no início. Você acredita que depois disso eu nunca mais voltei ao ginecologista, eu tomei raiva dele! (Maria)
Fui a médica e ela me disse que não era nada sério, pois não sentia dor nem inchaço. Então, pediu que eu observasse e, caso aparecesse alguma coisa, que era para procurar o médico. A partir daí, passaram-se seis a sete meses e o nódulo permanecia ali, ausência de dor fazendo com que eu não me preocupasse com este caroço (Júlia).

Escolha do procedimento cirúrgico. Os relatos pertinentes a esta subcategoria referem-se às dúvidas, à falta de conhecimento e ao descontentamento de algumas entrevistadas com relação às opções cirúrgicas e as repercussões destas no corpo. A importância da informação e conhecimento sobre a doença também está presente no processo decisório que envolve o tipo de procedimento cirúrgico a ser adotado. As falas sobre essa questão evidenciaram que, na maioria dos casos, a opção pela mastectomia foi realizada junto com a paciente, mediante a gravidade dos tumores encontrados:

No outro dia, recebi a equipe médica que conversou comigo, me deu apoio, informando sobre a mastectomia e que o meu caso ão era dos piores. O médico me explicou que esse tipo de cirurgia mexe muito com o emocional da gente (Júlia).

A médica não ponderou a retirada parcial da mama, a quadranctomia, né? Ela falou que seria mais seguro fazer a mastectomia total. Nesse período, eu fiquei muito ansiosa porque queria fazer o mais rápido possível a retirada da mama. Eu queria acabar com aquilo dentro de mim, ainda por cima porque estava em metástase na axila (Ana).

Uma entrevistada expressou insatisfação e desapontamento quanto ao fato de não lhe terem sido dadas garantias sobre qual opção cirúrgica seria adotada. Apesar da decepção, não questionou a atitude do médico, colocando-o numa posição de onipotência:

Só que o médico conversou comigo e me explicou o que poderia ser feito: tirar um quarto do seio ou o seio todo e me deu várias idéias que poderiam ser feitas. Na cirurgia é que ele ia saber qual seria a melhor forma. Foi tudo muito rápido, fiz a cirurgia e até então eu não sabia que estava sendo a mastectomia. Porque, na cirurgia, ele não fala, o meu marido não sabia, ninguém sabia (Elza).

Reação ao diagnóstico. As mulheres relataram sobre o choque emocional produzido ao receberem o diagnóstico do câncer de mama, a postura do médico e sua forma de relacionar-se com a paciente neste momento. Todas as informantes descreveram emocionadamente o momento do diagnóstico, em que o medo da morte e o desespero eram os sentimentos mais presentes:

Neste momento, eu fiquei muito revoltada, foi muito difícil, chorei muito... (Júlia).

Então, a primeira reação é essa, você fica até um pouco revoltada. E passa todo um questionamento de como foi a sua vida. Por que está acontecendo isso? Por que eu não fiz isso? Por que eu não fiz aquilo? Entendeu? Parece que você está marcado para morrer, bem antes do que você imaginava (Ana). 
Foi horrível, né? Porque você não tem noção do que é (Elza).

Quando você recebe o resultado não é fácil (Maria).

O nome já choca, entendeu? (Vera).

Eu e o mеu corpo. As falas referentes a essa categoria diziam respeito às dificuldades encontradas pelas informantes em lidar com o próprio corpo no período pós-mastectomia. O primeiro contato que as mulheres estabeleceram com o seu corpo operado foi com o espelho. Para algumas, o fato de observarem o corpo em que uma das mamas ou as duas não estão mais presentes provocou um sentimento de estranheza e muito sofrimento. Elza revelou que, no início, quando trocava de roupa, sempre ficava de costas para o espelho, porque não suportava observar o seu corpo. Além disso, relatou que nesse período, não conseguia tocar-se de forma alguma:

Tem um peito, o outro não tem. Não dá para você olhar no espelho, entendeu? Tomava banho sem ficar me olhando muito porque eu estava sem peito, eu não me olhava muito (Elza).

Você tem medo de olhar no espelho, a imagem te assusta mesmo, você está deficiente (Vera).

Tinha aquele negócio de você olhar e não ter mais seio (Júlia).

Uma das informantes relatou que, ao ver a sua imagem no espelho, a sua preocupação maior não foi com a perda da mama e sim com a perda do seu cabelo, consequência da quimioterapia. Segundo a mesma, a perda da mama é mais fácil para esconder, do que a queda do cabelo que representava um sinal mais vísível da doença:

Quando eu estava na época da quimioterapia, quando cai o cabelo, é horrível! Fui para a frente do espelho e passei a tesoura. O cabelo faz muita coisa (Maria).

Percepção de si mesma. Esta categoria está relacionada à auto-avaliação das entrevistadas antes e depois da mastectomia. Um acontecimento como o câncer de mama é considerado uma experiência única e inesquecível na vida da mulher acometida. Os relatos de algumas entrevistadas demonstram claramente que a doença provocou uma série de modificações em suas vidas, interferindo sobremaneira no modo como se sentem em relação a si mesmas e no modo como vêem a vida. Duas entrevistadas relataram que a experiência da proximidade da morte provocada pela doença fez com que modificassem toda a perspectiva de vida:

Seus valores mudam completamente, não é pouco não, muda muito. Você nasce de novo, é a palavra mais certa. Só passando pelo processo para saber. E essa mudança talvez seria o medo da morte (Vera).

Então, quando você imagina... fica sabendo da notícia, você imagina vou morrer daqui a dois meses. O alívio é tão grande que ao saber que você não vai morrer, que o resto é bobagem, você passa a ter um outro estilo de vida, tudo na sua vida é outra coisa, tudo, tudo. Além de ajudar outras pessoas que passam pela mesma situação, tenho que aprender alguma coisa com isso, mudando o meu jeito de pensar, mudando o meu jeito de agir, tudo entendeu? (Lúcia)
A fala das mulheres no que se refere a alteração na percepção do próprio corpo revela a insatisfação e não aceitação da perda da mama, gerando assim sentimentos de autodepreciação. Júlia destacou que sua vida mudou muito após a doença e que antes era uma pessoa mais alegre, gostava de divertir-se, namorar e fazer novas amizades. Hoje, considerase uma pessoa triste e impaciente. Fez uma auto-avaliação negativa de si mesma:

Sou outra mais revoltada, minha maneira de ser não é mais como antes, eu me irrito à toa. Essa cirurgia abalou a minha estrutura emocional, até hoje me sinto nervosa, tensa, irritada, não sou mais como antes. Cobro a mim mesma, não gosto de ficar dentro de casa, gosto de lidar com o público (Júlia).

A vestimenta representou uma outra referência que as mulheres fizeram às alterações de percepção do próprio corpo. A roupa desempenhou, em alguns casos, um importante papel durante o período pós-cirúrgico, uma vez que é por meio do uso de alguma vestimenta que a mulher procura ocultar a cicatriz pós-cirúrgica.

Elza considerava-se uma mulher muito vaidosa, tanto que as roupas decotadas eram os modelos que mais gostava de vestir antes da cirurgia. Relatou porém, que no período posterior a mastectomia, passou a evitar esses modelos, pois tinha vergonha do próprio corpo. Além disso, disse que quando era convidada pelo marido e a sua família para ir à praia, sentia-se muito constrangida. Porém, mesmo assim procurava fazer todas as vontades do marido:

Vai botar uma roupa e fica um buraco aqui; não pode usar uma blusa decotada. Mandei fazer uma blusa tipo camiseta de ginástica, botava sutiã, ia para a praia, mas péssima! Fui à praia, tudo isso empurrada pelos outros, porque, no fundo, eu não queria (Elza).

Eu e o olhar do outro. As informantes relataram as dificuldades encontradas na retomada da vida social após a mastectomia. Pôde-se obervar que o contato com o mundo externo despertou uma série de fantasias e medos, implicando numa mudança de comportamento em que mulheres mais sociáveis tornaram-se reservadas. Além disso, nas falas, pode-se observar claramente interiorizado pelas mulheres o estigma da doença. Segundo Vera, o seu maior medo era das pessoas perceberem o seu problema, tanto que realizou várias cirurgias plásticas, para que os sinais da doença não fossem percebidos:

Você não tira o sutiã perto de ninguém, você não troca de roupa perto de ninguém, mesmo estando tudo bonitinho, você acha que alguém vai perceber (Vera).

Lúcia expôs que se sentiu constrangida em alguns aspectos que pudessem chamar a atenção das pessoas para sua doença, pois em sua percepção a cicatriz deixada pela cirurgia desvelava uma realidade que lhe causava sofrimento. Entretanto, para lidar com esse sofrimento, disse que passou a comparar com outros tipos de perda, como por exemplo, a de um braço. Essa comparação lhe proporcionava um conforto nesses momentos, já que para ela, a mama representava um dos elementos da identificação feminina: 
Eu imagino que uma pessoa que passa por um determinado acidente, que tem uma cicatriz e tal... aquilo de vez em quando ele lembra da cicatriz e depois esquece, você acaba se acostumando (Lúcia).

Reconstrução da mama. Também foi uma questão contemplada em algumas falas. E, do ponto de vista da maioria das mulheres, representa uma possibilidade de recuperarem a sua feminilidade, sensualidade e erotismo.

Maria relatou não ter interesse em reconstruir a sua mama, porque não tem um companheiro. Pode-se entender que para ela a presença de um parceiro seria um fator de motivação para a realização da reconstrução da mama:

Mas, sei lá! Até agora não pintou, não! Eu não tenho um marido, não tenho nada. Eu acho que se eu tivesse que ficar despida perto de um homem... (Maria).

Relacionamento amoroso. Nessa categoria a maioira das mulheres relatou que percebeu algumas mudanças quando retomaram o relacionamento com o parceiro. No entanto, essa preocupação surgiu após os períodos de diagnóstico e tratamento, visto que durantes essas fases as mullheres estavam mais preocupadas em lutar pela sobrevivência. Os relatos referem-se ao comportamento do marido em relação à doença (apoio, compreensão, rejeição), às alterações positivas ou negativas no relacionamento afetivo do casal ou com namorados, no caso das mulheres solteiras e também à avaliação da vida sexual do casal antes e depois da mastectomia, sob o ponto de vista da informante. Sobre este fato, Vera disse que passou a dar atenção e investir no relacionamento com o seu marido depois que superou as fases de diagnóstico e de tratamento, que para ela foram muito traumatizantes. Além disso, relatou que ao retomar a sua vida sexual sentiu muita diferença e tinha medo do marido não aceitá-la mais. Mesmo tendo feito a reconstrução da mama, não permitia que o marido tocasse em seu seio durante a relação sexual, pois sentiase incomodada por ter perdido a sensibilidade dessa região. Disse que ele tem sido muito compreensivo e não se importou com as mudanças que ocorreram:

O tratamento é muito forte; a parte sexual não é nada, você nem lembra! / Meu marido não deixo tocar, não sei pelo fato do tempo, não sei! Você perde a sensibilidade (Vera).

Elza disse que, antes de realizar a reconstrução da mama, durante a relação sexual usava uma camiseta para esconder a parte operada e isso a incomodava muito. De acordo com a entrevistada, o seu marido não se importou com essas limitações. Enfatizou que a sua relação melhorou muito após a doença, o seu marido está mais atencioso, afetuoso, compreensivo e companheiro:

Não para o meu marido, mas para mim ficava ruim, eu já ficava de camisetinha, por exemplo; quando eu estava de baby dool ou camisola, eu não tirava a parte de cima. Ele tocava no seio normal porque aqui não tinha nada para ele tocar, era liso (...) Ele via isso como uma coisa normal, para ele não mudou nada, entendeu? Para ele, não fez diferença, poderia retirar os dois também que, para ele, não fazia diferença nenhuma (Elza).
Lúcia sobre esse assunto disse que a prótese utilizada em sua mama é semelhante à mama verdadeira, sendo que a única diferença está no tamanho que, às vezes, não é visível. Exprimiu a sua preocupação quando disse que, antes de se relacionar com alguém, o informa previamente que não quer expor a sua cicatriz, por isso transa somente utilizando o sutiã. Ressaltou ainda que é muito desconfortável ficar de sutiã durante a relação sexual; no entanto, isso não significa um obstáculo para o seu prazer, mesmo porque encontrou outros meios para lidar com essa situação:

\section{Aí, eu falava, olha: eu fiz uma cirurgia, tem uma cicatriz e não quero ficar mostrando. Então, eu vou transar de sutiã, e eles não se incomodam, eles não estão nem aí para o tal do seio, eles pegam normalmente. (...) Não é agradável transar de su- tiã, mas aí eu produzia o sutiã, comprava uma lingerie bem bonita e tal! E não me impede de, sabe, assim (...) não tem problema nenhum, além do que o outro seio é normal. Se ele quiser beijar e tal, tem o outro seio, entendeu? Mantenho dentro do sutiã, separo um pouquinho e fico numa boa. Graças a Deus! (Lúcia).}

Júlia revelou que na época da descoberta da doença acabou rompendo com o seu namorado, por achar que ele não aceitava a sua doença:

Ficou comigo, mas, depois nós terminamos, é claro! (enfatiza) Mas, não chegou a falar comigo o porquê que ele não aceitava, não conseguia viver comigo com esse problema e dizia para a minha irmã que eu não merecia isto! (chorou) (Júlia)

\section{Conclusão}

A análise das categorias possibilitou compreender não somente algumas faces da realidade das mulheres mastectomizadas a partir de sua própria percepção, como também as formas adotadas por elas para enfrentar a doença, assim como os diversos modos de expressar a sua sexualidade.

De acordo com a literatura, o diagnóstico do câncer de mama desencadeia uma série de conflitos emocionais, em que a morte e a perda da mama neste momento, passam a representar uma ameaça constante para a vida da mulher acometida. Inicialmente ao ser informada do diagnóstico, a preocupação maior da paciente volta-se para a sua sobrevivência. No momento do diagnóstico e das fases posteriores ao tratamento, a manutenção da vida é considerada mais importante do que a perda da mama propriamente dita, independentemente do procedimento cirúrgico a que a mulher foi submetida. Somente após afastada a possibilidade de morte é que a mulher irá voltar-se para a mutilação da mama e suas conseqüências.

É importante destacar que cada mulher reage a essas situações conforme algumas variáveis que dizem respeito à sua história de vida, ao contexto social, econômico e familiar de cada uma.

Como se pode observar, há dois momentos que são considerados marcantes pelas mulheres acometidas pelo câncer. O primeiro momento é caracterizado pela descoberta do cân- 
cer, que envolve também o diagnóstico e tratamento em que a batalha pela manutenção da vida é bastante evidente. As mulheres passam a conviver diariamente com a possibilidade de morte associada às representações presentes no imaginário social sobre o câncer de mama. Camon (1996) afirma que essa primeira fase

Traz em seu bojo uma configuração de total falta de sentido para o próprio significado existencial do paciente. É como se tudo que fosse preconcebido anteriormente desmoronasse e perdesse a configuração do real pela possibilidade de adoecer e as implicações de sua ocorrência (p. 183).

Num segundo momento, que envolve o período pós-cirúrgico há uma retomada do cotidiano das mulheres, após superarem o medo da morte. A partir da retomada dos relacionamentos sociais, atividades de lazer, trabalho e família é que surgem as preocupações relacionadas ao próprio corpo. Nesses contatos sociais ocorrem um defrontar-se com a realidade, fazendo com que as mulheres passem a reavaliar e reelaborar as suas potencialidades e as formas diferenciadas de relacionar-se com o próprio corpo e com os outros, principalmente o parceiro. A respeito dessa questão, Ferreira (1993) afirma que: "assim a mulher terá que se apropriar de um novo referencial de corpo em que uma de suas mamas (ou as duas) não estarão mais presentes” (p. 12). As entrevistadas relataram suas angústias referentes ao tratamento, com relação ao impacto da cirurgia no corpo. Neste sentido, a informação permeou todos os outros temas e foi destacada como um meio importante para diminuir as expectativas do tratamento, assim como, a ansiedade, a insegurança e o medo frente à possibilidade de mutilação. Estudos que pudessem aprofundar essa questão seriam de grande relevância para que novas formas de intervenção psicológica fossem criadas, a fim de que as pacientes diagnosticadas com o câncer de mama possam ser melhor orientadas pelos profissionais de saúde, implicando em uma diminuição e manejo do estresse provocado pelas limitações impostas pela doença.

Os temas levantados revelam claramente as dificuldades encontradas pelas informantes para se adequarem a uma nova situação, a perda da mama, que comprometeu de uma certa forma todos os âmbitos de suas vidas. As alterações do próprio corpo implicam também em transformações afetivas, refletidas na forma de como as mulheres percebem a si mesmas e na forma de vivenciarem a vida. O processo de (re)adequação da sexualidade a esse novo referencial de corpo ocorre lentamente.

Assim, para algumas entrevistadas, as mudanças provocadas pela doença foram consideradas como positivas, porque fizeram com que valorizassem ainda mais as suas vidas e potencializassem novos modos de expressar a própria sexualidade. Nessas situações, especificamente no que se refere às relações amorosas, foram muito valorizadas a dimensão afetiva da sexualidade em suas formas de sedução, troca de carícias, cumplicidade, toque e outros. Contrariamente, outras mulheres revelaram que a mastectomia lhes causou grande sofrimento devido às dificuldades em estabelecerem uma nova relação com o próprio corpo e com o par- ceiro. Nesse contato, conforme relatos, foram despertados medos e fantasias produzidos pelo estigma da doença, provocando mudanças no comportamento. As entrevistadas revelaram que antes do câncer eram mais sociáveis e alegres; porém, após a doença tornaram-se reservadas, tristes e procuram isolar-se do contato social. Além disso, no que se refere aos relacionamentos amorosos, associam a sexualidade ao aspecto genital, e durante as relações sexuais sentem-se inibidas, e tentam ocultar a mama mutilada.

\section{Referências}

Bardin, L. (1977). Análise de conteúdo. Lisboa: Edições 70.

Boff, A. R. (1999). Repercussões associadas à terapêutica cirúrgica de mulheres com câncer de mama. Dissertação de Mestrado não-publicada, Universidade de São Paulo, São Paulo.

Camon, A. V. (1996).O imaginário e o adoecer: um esboço de pequenas e grandes dúvidas. In A. V. Camon (Orgs.), E a psicologia entrou no hospital (pp. 181-213). São Paulo: Pioneira.

Carver, S. C. (1993). How coping mediates the effects of optimism on distress: a study of woman with early stage breast cancer. Journal of Personality and Social Psychology, 65(2), 375-389.

Chiozza, L. (1987). Por quê adoecemos? A história que se oculta no corpo. Campinas: Papirus.

Cox, T., \& Mackay, C. (1981). Psychosocial factors and psychophysiological mechanisms in the etiology and development of cancer. Social Science and Medicine, 43(3), 215-225.

Dousset, M. P. (1999). Vivendo durante um câncer (V. Ribeiro, Trad.). São Paulo: Editora da Universidade Federal de Santa Catarina.

Farstein, E. (1989). Ideologia, normas médicas e racionalidade epidemiológica: o caso do câncer genital feminino. Cadernos do Instituto de Medicina Social, 5(1), 175-186.

Ferreira, M. S. L. M. (1993). A mulher mastectomizada e suas preocupações: experiências de um trabalho multiprofissional. Revista de Atualização em Ginecologia e Obstetrícia (Goiás: Editorial Moreira Júnior), 8(6), 12.

Folkman, S., \& Lazarus, R. (1984). Stress, appraisal, and coping. Nova York: Springer.

Gandini, C. R. (1995). Câncer de mama: evolução da eficácia adaptativa em mulheres mastectomizadas. Tese de Doutorado não-publicada, Universidade de São Paulo, São Paulo.

Gimenes, M. G. G. (1997). A teoria do enfrentamento e suas implicações para sucessos e insucessos em Psicologia. In M. G. G. Gimenes \& M. H. Fávero (Orgs.), A mulher e o câncer (pp. 111-147). São Paulo: Editorial Psy.

Gimenes, M. G. G., \& Queiroz, E. (1997). As diferentes fases de enfrentamento durante o primeiro ano após a mastectomia. In M. G. G. Gimenes \& M. H. Fávero (Orgs.), A mulher e o câncer (pp.173-195). São Paulo: Editorial Psy.

Gomes, R. (1987). Manual de oncologia básica. Campinas: Revinter.

Gonçalves, M. C. S., \& Dias, R. M. (1999). A prática do auto-exame da mama em mulheres de baixa-renda: um estudo de crenças. Estudos de Psicologia, 4(1), 141-159.

Instituto Nacional do Câncer (1997). Falando sobre doenças da mama: ProOnco. Rio de Janeiro: Coordenação de Programas de Controle do Câncer/ Ministério da Saúde.

Instituto Nacional do Câncer (2000). Falando sobre doenças da mama: ProOnco. Rio de Janeiro: Coordenação de Programas de Controle do Câncer/ Ministério da Saúde.

Kolb, L. C. (1980). Psiquiatria Clínica. Rio de Janeiro: Interamericana.

Kolch, O. L. V. (1984). Testes projetivos gráficos no diagnóstico psicológico. São Paulo: EPU.

Kovács, M. J., Amorim, A. C. C., Filho, \& Sgorlon, L. C. A. (1998). Avaliação da qualidade de vida em pacientes oncológicos em estado avançado da 
doença. In M. M. M. J. Carvalho (Org.), Psico-oncologia no Brasil: resgatando o viver (pp. 159-185). São Paulo: Summus.

Lim, J. (1995). Sexuality of woman after mastectomy. Annals of the Academy of Medicine (Cingapura), 25(5), 660-662.

Malzyner, A. (1997). Metamorfose de uma angústia: o tratamento do câncer de mama de Halsted ao BRCA-1. In M. G. G. Gimenes \& M. H. Fávero (Orgs.), A mulher e o câncer (pp. 72-107). Campinas: Editorial Psy.

Minayo, S. C. M. (1999). O desafio do conhecimento. São Paulo: Hucitec.
Sant’Ana, D. B. (1997). A mulher e o câncer na história. In M. G. G. Gimenes, \& M. H. Fávero (Orgs.), A mulher e o câncer (pp. 43-70). Campinas: Editorial Psy.

Segal, M. S. (1984). Desfazendo mitos. São Paulo: Ágora.

Seidl, E. \& Gimenes, M. G. G. (1997). A prática do auto-exame na prevenção do câncer de mama. In M. G. G. Gimenes \& M. H. Fávero (Orgs.), A mulher e o câncer (pp.260-290). Campinas: Editorial Psy.

Sontag, S. (1984). A doença como metáfora. Rio de Janeiro: Edições Graal.

\section{Nota}

1 Essa escala avalia ansiedade e depressão; tem sido amplamente utilizada para avaliar os transtornos do humor em pacientes com doenças físicas na situação hospitalar.

Tânia Pires Duarte, psicóloga e mestre em Psicologia Social.

Ângela Nobre de Andrade, doutora em Psicologia Clínica e professora do Programa de Pós-Graduação em Psicologia, Universidade Federal do Espírito Santo.

Endereço para correspondência: Rua Comissário Octávio Queiroz, 20, Apto. 301, Bloco 8, Jardim da Penha, Vitória/ES. Tel.: (27) 3315-8353/cel.9953-1364. E-mail: tania.du@bol.com.br 